\title{
Ovarian androgens protect against bone loss in rats made oestrogen deficient by treatment with ICI 182,780
}

\author{
C K Lea and A M Flanagan
}

Department of Histopathology, Imperial College of Science, Technology and Medicine at St Mary's, Norfolk Place, London, UK

(Requests for offprints should be addressed to A M Flanagan, Department of Histopathology, Imperial College of Science, Technology and Medicine at St Mary's, Norfolk Place, London W2 1PG, UK)

\begin{abstract}
We tested the hypothesis that ovarian androgens play a role in protecting against cancellous bone loss in oestrogendeficient states and that conversion of androgens to oestrogens is not catalysed by aromatase P450 in the bone or bone-marrow microenvironment. We did this by administering the anti-oestrogen, ICI 182,780, alone and in combination with the anti-androgen, Casodex, and compared the effects on the skeleton with those of ovariectomy. We found that rats subjected to ovariectomy lost significantly greater cancellous bone volume compared with those treated with ICI 182,780, but that combination anti-oestrogen and anti-androgen therapy resulted in bone loss equivalent to that in ovariectomised animals. The
\end{abstract}

skeletal-protective effect of preserving the ovaries in animals which had been chemically ovariectomised was attributed to suppression of osteoclast parameters. Taken together, these data suggest that a reduction in ovarian androgens accentuates the increase in osteoclast number and the reduction in cancellous bone volume which occurs in oestrogen-deficient states. Failure to detect transcripts for aromatase cytochrome P450 in the bone and bonemarrow of rats provides supportive evidence that androgens mediate their skeletal-protective effect directly and not by peripheral conversion to oestradiol.

Journal of Endocrinology (1999) 160, 111-117

\section{Introduction}

The ovary produces both oestrogens and androgens, but the physiological importance of the latter in the female is frequently overlooked. However, we and others have recently demonstrated that physiological plasma levels of androgens protect against bone loss in rats (Goulding \& Gold 1993, Tobias et al. 1994, Lea et al. 1996, Lea \& Flanagan 1998, Lea et al. 1998). Our data suggest that physiological levels of androgens only inhibit bone resorption if rats are oestrogen deficient (Lea \& Flanagan 1998, Lea et al. 1998). In addition, androgens play an important role in bone formation in rats (Tobias et al. 1994, Gallagher et al. 1996, Lea et al. 1996), and others have reported that this may also be the case in the oestrogen-replete state in humans (Raisz et al. 1996).

One aim of this study was to test the hypothesis that ovarian androgens exert a skeletal-protective effect in oestrogen-deficient states. The second aim was to determine whether the conversion of androgens to oestrogens could be catalysed in the bone/bone-marrow (BM) microenvironment, because if this were the case, androgens might mediate their effect on the skeleton indirectly, through oestrogens. Evidence exists that peripheral conversion of gender steroids in skeletal tissue plays an important role in modulating bone turnover (Vittek et al.
1974, Frisch et al. 1980, Bruch et al. 1992, Purohit et al. 1992, Nawata et al. 1995, Lea et al. 1997). Specifically, it has been proposed, based largely although not exclusively on results from in vitro studies (Sasano et al. 1997), that conversion of androstenedione (adione) to oestrone, and testosterone to oestradiol may be catalysed by aromatase cytochrome P450 (P450arom) in the BM microenvironment. Previously, however, we have failed to detect these transcripts in normal primary (uncultured) human bone and BM (Lea et al. 1997). Hence, we chose to investigate this question further to see if our findings were similar in murine species.

To achieve our aim, we compared the effect of ovariectomy and treatment with the anti-oestrogen, ICI 182,780, and/or the anti-androgen, Casodex, on the skeleton in female rats. ICI 182,780 is a steroidal antioestrogen which antagonises the effects of oestrogen (Plourde et al. 1994, 1995) by inhibiting oestrogeninduced activation of the oestrogen response element (Yang et al. 1996). Similar compounds are known to bind both oestrogen receptor $\alpha$ and oestrogen receptor $\beta$ (Paech et al. 1997). ICI 182,780 acts for the most part as an anti-oestrogen (Wakeling et al. 1991), but it has been reported to act as an agonist on human endometrial cells (Tonetti et al. 1998) and also on human bone-marrow cells in vitro (Sarma et al. 1995). However, the mechanism by 
which this occurs is not clear. ICI 182,780 does not mediate an effect through the androgen receptor, and there are no reports to suggest that it interacts with Casodex. Casodex is a peripherally selective non-steroidal anti-androgen which mediates its effects by antagonising androgen receptor binding. It has no other discernible properties and does not appear to exert agonist effects (Furr et al. 1987, Furr 1988, 1989).

\section{Materials and Methods}

\section{Animal experimentation and histomorphometry}

Female Sprague-Dawley rats were purchased from Harlan Olac Ltd (Bicester, Oxon, UK) and housed at $21{ }^{\circ} \mathrm{C}$ with a $12 \mathrm{~h}$ light: $12 \mathrm{~h}$ darkness cycle and fed rat chow (Lillico, Betchworth, Surrey, UK) and water. The animals were pair-fed.

Experiment 1 Thirteen-week-old animals, with an average weight of $253 \mathrm{~g}$ (range: $228-275 \mathrm{~g}$ ), were subjected to ovariectomy or a sham operation under halothane anaesthesia using a dorsal approach, on day 1 . The animals were divided into five treatment groups each containing ten animals: group 1, sham ovariectomy (sham); group 2, ovariectomy (ovx); group 3, sham+ICI 182,780; group 4, sham+ICI 182,780+Casodex; group 5, sham+Casodex. The anti-androgen, Casodex (Furr 1989), and the oestrogen antagonist, ICI 182,780 (Wakeling 1993) were kindly provided by Dr B M Vose (Zeneca Pharmaceuticals, Macclesfield, UK). Casodex (1 mg/kg/day) was dissolved in saline and $0.5 \%$ Tween and given orally daily. ICI $182,780(1 \mathrm{mg} / \mathrm{kg} /$ day) was dissolved in corn oil (Sigma Chemical Co., Poole, Dorset, UK) and administered s.c. daily (Wakeling 1993). Calcein (Sigma Chemical Co.) $(30 \mathrm{mg} / \mathrm{kg})$ and tetracycline hydrochloride (Lederle Laboratory, Gosport, Hants, UK) $(25 \mathrm{mg} / \mathrm{kg})$ were injected i.p. 14 and 7 days prior to the animals being killed. After ninety days treatment, the animals were killed by cervical dislocation.

The uteri were removed and weighed and ovariectomy was confirmed by the absence of ovarian tissue. The tibiae were cleaned of soft tissue, fixed in 70\% alcohol for $24 \mathrm{~h}$, dehydrated through graded alcohols and embedded without decalcification in London Resin (London Resin Co. Ltd, Basingstoke, Hants, UK). Longitudinal sections of the proximal metaphysis were cut using a Reichart-Jung microtome (Leica Ltd, Germany). Sections $(5 \mu \mathrm{m})$ were stained with toluidine blue and unstained sections $(12 \mu \mathrm{m})$ were cut for fluorescent microscopy. Bone histomorphometry was performed using transmitted and epifluorescent microscopy linked to a computer-assisted image analyser (Seescan Ltd, Cambs, UK). Bone volume and surface parameters were measured by tracing the relevant features with a cursor on the video screen. Cancellous bone volume/trabecular volume (BV/TV) measurements were performed at $\times 40$ magnification and the surface par- ameters were measured at $\times 400$ magnification. All sections were analysed without knowledge of the group from which they came.

$\mathrm{BV} / \mathrm{TV}$ at the proximal metaphyseal cancellous bone was measured on four non-consecutive sections. A standard area of $2 \mathrm{~mm}^{2}$ (at least $2 \mathrm{~mm}$ from the growth plate to exclude the primary spongiosa) was measured. Static parameters were measured in the same way as that described for $\mathrm{BV} / \mathrm{TV}$ and included osteoblast surface bone surface (Ob.S/BS), osteoclast surface (Oc.S/BS) and osteoclast number (NOc./BS). Longitudinal growth rate (LGR) was derived by measuring the distance between the tetracycline and the calcein fluorescent bands that parallel the growth plate at four equally placed sites per section and dividing by the time interval between the two injections. The bone formation rate (BFR/BS; tissue level, total surface referent) was calculated from the product of the percentage of the trabecular bone surface with a double fluorochrome label (dLS/BS) and the mineral apposition rate (MAR): the former was obtained by measuring the percentage of the trabecular bone surface, covered by two fluorochrome labels and the latter by dividing the inter-label distance by the time interval between the injections of the labels in the corresponding area. The BFR values were not corrected for label escape errors. Appositional rate values were not corrected for the obliquity of the plane of section of cancellous bone.

The results were analysed using Fisher's least significant difference for multiple comparisons in a one-way analysis of variance and expressed as means \pm S.E. Significance was considered when $P<0 \cdot 05$. Statview 4.0 (Abacus Concepts, Cupertino, CA, USA) was used to analyse the results.

\section{Experiment 2: collection and RNA extraction of} tissue Details of the animals from which the tissue was removed for this experiment have previously been published (Lea \& Flanagan 1998). In brief, at the beginning of the experiment, the animals were 13 weeks old with an average weight of $216 \mathrm{~g}$. The animals were grouped as follows: sham-operated, ovariectomised, and ovariectomised treated with $1.5 \mathrm{mg}$ slow release androstenedione (adione) pellet. The adione and testosterone plasma levels in the adione-treated rats were returned to just below those in the sham-operated group. The animals were killed after 21 days and tissue was removed. The animals were maintained and killed as described in experiment 1 . Rat abdominal adipose tissue and ovaries (in the sham animals) were removed from animals and snap-frozen in liquid nitrogen. The tibial ends, not used for histomorphometry, were cut and discarded and the BM was flushed through with RNAzol B (Biogenesis, Bournemouth, Hants, UK); the metaphyseal cortical bone was washed with diethyl pyrocarbonate (Sigma Chemical Co.) (DEPC)-treated water and also snap-frozen. BM from the femora was flushed out using PBS, disaggregated into a single cell solution and cultured at a density of $2 \times 10^{7}$ 
cells/T75 tissue culture flask (Corning Glass Works, Corning, NY, USA) in Minimum Essential Medium containing penicillin and streptomycin (all from Gibco, Life Technologies, Paisley, Strathclyde, UK). After 7 days, when the cells were sub-confluent, the cells were frozen at $-70{ }^{\circ} \mathrm{C}$.

Total RNA was extracted from the frozen tissue using RNAzol B, according to the manufacturer's instructions. The bone was ground into fine particles using a mortar and pestle in the RNAzol, but otherwise the RNA extraction process was similar to other tissues. RNA was assessed by spectrophotometric absorption at $260 \mathrm{~nm}$. Total RNA was also extracted from R2C cells, a rat Sertoli-Leydig cell line (ECACC, Porton Down, Wilts, UK), which constituitively expresses P450arom, and other tissues which are also known to express this mRNA, including primary human placenta, rat testis and brain.

\section{RT-PCR for P450arom $m R N A$}

Amplification of P450arom mRNA was carried out using the same method and primers (Oswel DNA, Edinburgh, UK) as previously described (Bulun \& Simpson 1994). The 20 mer $3^{\prime}$ oligonucleotide used for initial primer extension was $5^{\prime}$ TTGTTGTTAAATATGATGCC 3'; the 20 mer $5^{\prime}$ oligonucleotide used during amplification was $5^{\prime}$ ATACCAGGTCCTGGCTACTG 3'. The sense and antisense primers recognised identical human and rat sequences. Two micrograms total RNA were used for primer extension at $37^{\circ} \mathrm{C}$ for $60 \mathrm{~min}$ using $100 \mathrm{pmol} \mathrm{3}$ oligonucleotide, $1 \mathrm{mmol} / \mathrm{l}$ of each dNTP (final concentration) (Pharmacia, St Albans, Herts, UK), and $400 \mathrm{U}$ Moloney murine leukemia virus reverse transcriptase (MMLV-RT) (Gibco Life Technologies) in a final volume of $50 \mu \mathrm{l}$. The same buffer was used for the primer extension and the amplification step; it comprised $\mathrm{KCl}$ (50 mmol/l), Tris-HCl (20 mmol/l; pH 8.3), $\mathrm{MgCl}_{2}$ (4 mmol/l), and $0.1 \mathrm{mg} / \mathrm{ml}$ nuclease-free BSA (all purchased from Sigma Chemical Co.). The reaction was stopped with RNAse A (1 mg/ml) (Sigma Chemical Co.).

The master amplification mix contained 50 pmol $3^{\prime}$

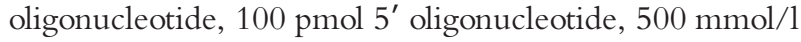
(final concentration) of each dNTP in a volume of $100 \mu$ l. Eighty microlitres amplification master mix, $20 \mu \mathrm{l}$ initial primer extension reaction, and $0.5 \mathrm{U}$ Taq polymerase (Applied Biosystems, Leatherhead, Surrey, UK) were amplified using 35 repeated cycles of $93{ }^{\circ} \mathrm{C}$ for $1 \mathrm{~min}$, $42{ }^{\circ} \mathrm{C}$ for $1 \mathrm{~min}$ and $72{ }^{\circ} \mathrm{C}$ for $1 \mathrm{~min}$. Amplification products were separated by electrophoresis on a $2 \%$ agarose gel (Sigma Chemical Co.), and visualised with ethidium bromide (Sigma Chemical Co.).

\section{Co-amplification of rat and human RNA and Southern blot analysis}

Total RNA from rat bone and BM was mixed with equal amounts of human placental RNA $(1 \mu \mathrm{g})$ (which had previously been shown to be positive for P450arom mRNA). The mixed samples were reverse-transcribed to cDNA using the P450arom specific primers which detect sequences in both species. These samples were then amplified for P450arom transcripts by 35 cycles of PCR. The products from each PCR tube were divided into two equal parts, separated by electrophoresis and transferred to blotting membranes (Amersham, Little Chalfont, Bucks, UK) by capillary elution. The 23 mer oligonucleotide, $5^{\prime}$ TAGTTGCTGTGCTTCATCACATG $3^{\prime}$, was used as a probe for the rat amplification product, and was complementary to nucleotides $391-413$ of the rat cDNA. The sequence of the 23 mer oligonucleotide 5' TAATGATTGTGCTTCATTATGTG $3^{\prime}$ used as a probe for the human amplification product was complementary to nucleotides 340-362 of the human cDNA (Bulun \& Simpson 1994).

The rat and human $5^{\prime}$ oligonucleotide probes were end-labelled with $\left[\gamma^{32} \mathrm{P}\right]$ ATP and hybridised overnight at $55{ }^{\circ} \mathrm{C}$ and $59{ }^{\circ} \mathrm{C}$ respectively. The autoradiographs were exposed to the blotting membranes for various times (2-6 days).

\section{RT-PCR of rat interleukin-6 (IL-6)}

Two micrograms of each total RNA were reversetranscribed in a final volume of $50 \mu$ l. This was carried out using the $3^{\prime}$ oligonucleotide, 5' GCTTAGGCATAGC ACACTAGG $3^{\prime}$, under the same conditions as described for primer extension of P450arom mRNA. The cDNA was amplified by PCR; 35 repeated cycles of $94^{\circ} \mathrm{C}$ for $1 \mathrm{~min}, 60^{\circ} \mathrm{C}$ for $30 \mathrm{~s}$, and $72{ }^{\circ} \mathrm{C}$ for $30 \mathrm{~s}$ in an amplification mixture consisting of $100 \mathrm{pmol} 5^{\prime}$ AGCCAG TTGCCTTC-TTGGGAC 3', 50 pmol of the oligonucleotide used for the initial extension, $200 \mathrm{mM}$ of each dNTP (final concentration), $1.5 \mathrm{mM} \mathrm{MgCl}$ and buffer IV (supplied with the enzyme). The IL-6 PCR products were confirmed by digestion with MseI and DpnII.

\section{Results}

Experiment 1 Ovariectomy resulted in a significant increase in body weight compared with all other groups despite pair-feeding, whereas the animals treated with ICI 182,780 did not increase their body weight. The antioestrogen treatment reduced the uterine weight to that in the ovariectomised rats. Casodex treatment alone had no effect on uterine weight and in combination with ICI 182,780 did not further reduce it below that induced by the anti-oestrogen (Table 1). ICI 182,780 had no effect on the LGR of sham-operated rats, whereas LGR was significantly increased in the ovariectomised group (Table 1).

The cancellous bone volume in the rats treated with ICI 182,780 was significantly greater than that measured in the 
Table 1 Effect of ICl 182,780 and Casodex, alone or in combination, on body weight, uterine weight and LGR. Results are means \pm S.E.M.

\begin{tabular}{|c|c|c|c|c|c|}
\hline & Sham + vehicle & Ovx + vehicle & Sham+ICI 182,780 & $\begin{array}{l}\text { Sham + ICI 182,780 } \\
\text { +Casodex }\end{array}$ & Sham + Casodex \\
\hline Body weight (g) & $275 \cdot 75 \pm 3 \cdot 70$ & $336 \cdot 13 \pm 5 \cdot 14^{*}$ & $280 \cdot 38 \pm 4 \cdot 91$ & $277 \cdot 00 \pm 4 \cdot 05$ & $279 \cdot 50 \pm 4 \cdot 23$ \\
\hline Uterine weight (mg) & $542 \cdot 18 \pm 38 \cdot 62^{*}$ & $175 \cdot 91 \pm 14 \cdot 88^{* *}$ & $200 \cdot 03 \pm 9 \cdot 77^{* *}$ & $187 \cdot 60 \pm 8 \cdot 61^{* *}$ & $618 \cdot 47 \pm 35 \cdot 29$ \\
\hline
\end{tabular}

ovariectomised rats (Table 2). However, combination treatment with ICI 182,780 and Casodex for 90 days reduced the cancellous bone volume to that in the ovariectomised rats (Table 2). As previously reported (Lea et al. 1996), Casodex alone exerted no effect on this parameter. Osteoclast parameters were increased in the animals treated with ICI 182,780 to values mid-way between those in the ovariectomised rats and the shamoperated rats. The combination of ICI 182,780 and Casodex treatment elevated osteoclast parameter values to those in the ovariectomised animals (Table 2).

Static and dynamic parameters of bone formation were increased as a consequence of ovariectomy, but they were not increased in response to ICI 182,780 treatment. In contrast, these parameters were significantly suppressed in response to Casodex alone (Table 2).

\section{Detection of P450arom transcripts by RT-PCR}

P450arom transcripts were not detected in any of the samples of primary bone or BM from the sham-operated, ovariectomised or adione-treated rats (Fig. 1), and these results were confirmed by Southern blot (Fig. 2). Co-amplification of rat and human tissues excluded the possibility of both RT and PCR failure (Fig. 2). In addition, the detection of IL-6 mRNA in the same specimens of bone and BM, and $\beta$-actin in adipose tissue demonstrated that the RNA was of good quality (Fig. 1). The expression of $\mathrm{P} 450$ arom $\mathrm{mRNA}$ in cultured BM from the same animals demonstrates that failure to detect the transcripts in primary bone and BM was not due to the probes failing to detect the P450arom transcripts in this tissue.

\section{Discussion}

This study demonstrates that, after ninety days postovariectomy, rats have lost $75 \%$ of their cancellous volume, as against $60 \%$ as a result of chemical blocking of oestrogen with ICI 182,780. Those rats in which the ovaries were preserved but which were 'oestrogen-deficient' had 70\% more cancellous bone volume compared with ovariectomised animals, that is, the 1CI 182,780-treated rats had $8.5 \%$ cancellous bone compared with $5 \%$ in the ovariectomised rats. This implies that the ovary offers a minor but significant skeletal-protective effect in the absence of oestrogen. However, our data are entirely consistent with the well documented observation that the major effect of gender hormones is via the oestrogen receptor.

Our results indicate that the protective effect was mediated by androgens, because combination antioestrogen and anti-androgen therapy resulted in bone loss equivalent to that seen post-ovariectomy (Lea \& Flanagan 1998). Furthermore, the skeletal-protective effect provided as a result of preserving the ovaries in animals treated with ICI 182,780 for ninety days, was similar to the protective effect produced in ovariectomised rats in response to $1.5 \mathrm{mg}$ slow-release pellet of adione (which restored their androgen plasma levels to pre-ovariectomy levels) (Lea \& Flanagan 1998).

Table 2 Effect of ICl 182,780 and Casodex, alone or in combination, on static and dynamic parameters of bone histomorphometry. Results are means \pm S.E.M

\begin{tabular}{|c|c|c|c|c|c|}
\hline & Sham + vehicle & Ovx+vehicle & Sham + ICI 182,780 & $\begin{array}{l}\text { Sham + ICI 182,780 } \\
\text { +Casodex }\end{array}$ & Sham + Casodex \\
\hline BV/TV (\%) & $20 \cdot 94 \pm 0.57^{*}$ & $5 \cdot 04 \pm 0.27^{* *}$ & $8 \cdot 48 \pm 0 \cdot 31$ & $5 \cdot 69 \pm 0 \cdot 30^{* *}$ & $18 \cdot 90 \pm 0 \cdot 36$ \\
\hline Oc.S/BS (\%) & $0.59 \pm 0.02 *$ & $1 \cdot 57 \pm 0.04^{* *}$ & $0 \cdot 86 \pm 0 \cdot 30$ & $1 \cdot 52 \pm 0.04^{* *}$ & $0.60 \pm 0.03$ \\
\hline NOc./BS (\%) & $0 \cdot 21 \pm 0.01^{*}$ & $0.61 \pm 0.02^{* *}$ & $0.39 \pm 0.02$ & $0 \cdot 57 \pm 0.01^{* *}$ & $0 \cdot 18 \pm 0 \cdot 02$ \\
\hline Ob.S/BS (\%) & $1.06 \pm 0.04^{*}$ & $2 \cdot 46 \pm 0.06^{\dagger}$ & $1.50 \pm 0.04$ & $1 \cdot 53 \pm 0.03^{\|\| \mid}$ & $1 \cdot 22 \pm 0 \cdot 07$ \\
\hline $\mathrm{dLS} / \mathrm{BS}(\%)$ & $1 \cdot 61 \pm 0 \cdot 10^{*}$ & $5 \cdot 21 \pm 0.09^{\dagger}$ & $2 \cdot 33 \pm 0.08^{\dagger}$ & $1 \cdot 37 \pm 0 \cdot 10^{\|}$ & $0 \cdot 87 \pm 0 \cdot 07^{* * *}$ \\
\hline $\mathrm{MAR}(\mu \mathrm{m} /$ day $)$ & $1 \cdot 04 \pm 0 \cdot 03$ & $1 \cdot 76 \pm 0.03^{\dagger}$ & $1 \cdot 08 \pm 0.05^{\alpha}$ & $0 \cdot 75 \pm 0 \cdot 04^{* * *}$ & $0 \cdot 73 \pm 0 \cdot 04^{* * *}$ \\
\hline BFR/BS $\left(10^{-2} \mu \mathrm{m}^{-2}\right.$ day $)$ & $1.66 \pm 0.08$ & $9 \cdot 16 \pm 0 \cdot 13^{\dagger}$ & $2 \cdot 51 \pm 0 \cdot 14^{\dagger}$ & $1 \cdot 02 \pm 0.07^{\| * * *}$ & $0.64 \pm 0.60^{* * *}$ \\
\hline
\end{tabular}

${ }^{*} P<0 \cdot 0001$ vs all groups except sham + Casodex. ${ }^{* *} P<0 \cdot 0001$ vs sham + vehicle, sham $+I C l 182,780$, and sham + Casodex. ${ }^{\dagger} P<0 \cdot 0001$ vs all groups. ${ }^{\alpha} P<0 \cdot 001$ vs all groups except sham + vehicle. $\| P<0.0002$ vs sham + Casodex. ${ }^{\| I} P<0.001$ vs sham + Casodex. ${ }^{* * *} P<0 \cdot 001$ vs sham + vehicle. 


\section{$\begin{array}{llllllllll}1 & 2 & 3 & 4 & 5 & 6 & 7 & 8 & 9 & 10\end{array}$}

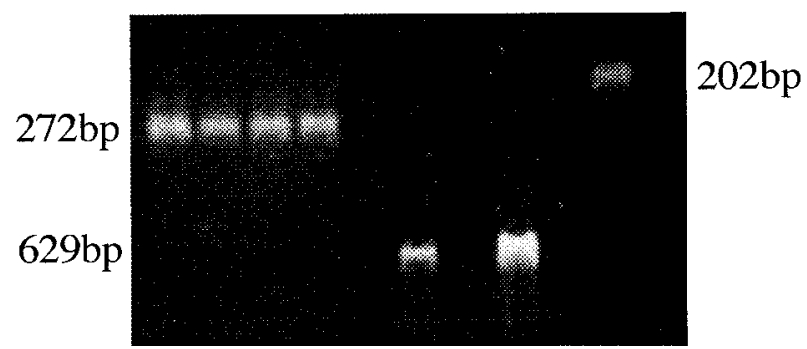

Figure 1 RT-PCR of P450arom transcripts (272 bp) in total RNA extracted from bone and BM in ovx rats on day 21. Lane 1, cultured BM; lane 2, R2C cells; lane 3, brain; lane 4, ovary; lane 5, primary cortical bone; lane 7 , primary $\mathrm{BM}$; lane 9 , adipose tissue. Lanes 6 and 8 show RT-PCR products for IL-6 transcripts (629 bp) from the same samples of CDNA which were tested for the presence of P450arom transcripts in lanes 5 and 7. Lane 10 shows RT-PCR products for $\beta$-actin from the same sample of cDNA which was tested for the presence of P450arom transcripts in lane 9. Similar results were obtained from samples from three other sham animals and three ovx rats, and ovx rats treated with $5 \mathrm{mg}$ adione pellets.

Our observations indicate that the partial skeletalprotective effect provided by preserving ovarian tissue in the absence of oestrogen was attributed to the prevention of osteoclast parameters being elevated to those levels in the ovariectomised rats. As demonstrated previously, the anti-resorptive effect of androgens appears to exert an effect in the absence of oestrogen (Lea \& Flanagan 1998,

\section{7}

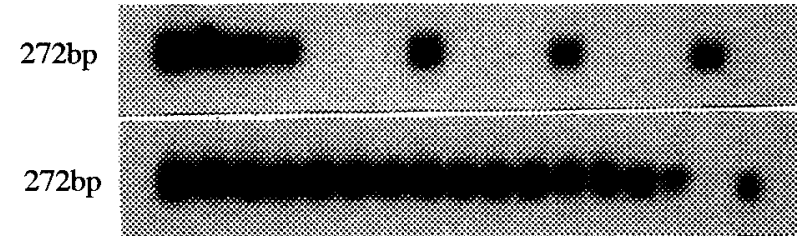

Figure 2 Southern blot analysis for rat P450 aromatase cDNA. Co-amplification of human placental total RNA, known to express P450arom, with rat cortical bone, rat BM and rat adipose tissue excludes failure of RT-PCR as an explanation for failure to detect transcripts for P450arom in primary BM from sham, ovx rats, and ovx rats treated with $5 \mathrm{mg}$ adione pellets. The upper panel shows PCR products labelled with rat P450 cDNA. The lower panel shows the same PCR products labelled with human P450arom cDNA. Hybridisable products were present in all the samples except lane 16, where only rat RNA was present, indicating that RT and PCR were successful. Lane 1, cultured ovx rat BM; lane 2, R2C cells. Lanes 3-7 represent RNA extracted from sham rats. Lane 3, rat brain; lane 4, rat ovary; lane 5, primary cortical bone; lane 6, primary BM; lane 7 , adipose tissue. Lanes $8-11$ represent RNA extracted from ovx rats. Lane 8 , brain; lane 9, primary cortical bone; lane 10, primary BM; lane 11, adipose tissue. Lanes 12-15 represent RNA extracted from adione-treated rats. Lane 12, rat brain; lane 13, primary cortical bone; lane 14, primary BM; lane 15 , adione adipose tissue. Lane 16, rat brain RNA only. Lane 17, human placental RNA only. Similar results were found for two other sets of rats.
Lea et al. 1998). We accept that assessment of osteoclast parameters is difficult, and caution must be used when interpreting the data. However, we argue that because: (1) ten animals were included per group, (2) the data were analysed blind, (3) the difference was highly significant $(P<0 \cdot 0001)$ and $(4)$ the results throughout the study were consistent, our findings are sound. Furthermore, the results in this study are supported by our previous reports (Lea \& Flanagan 1998, Lea et al. 1998). However, in a twentyone-day experiment, Gallagher et al. (1993) did not detect a significant difference in the cancellous bone volume between rats treated with ICI 182,780 and ovariectomised rats, nor did they detect an increase in osteoclast number in response to the ICI compound. These differences can probably be accounted for by the greater number of animals per variable in our experiment (10 vs 7), and the longer duration (90 vs 21 days) of our experiment compared with theirs.

Ovariectomy resulted in the expected increase in bone formation parameters which are considered to be a response to increased bone resorption (Wronski et al. 1988). However, a similar increase was not observed in response to ICI 182,780 treatment, despite the increase in osteoclast parameters. In addition, ICI 182,780 exerted no effect on the LGR. These findings were surprising, but not entirely unexpected, as this has been reported previously (Gallagher et al. 1993). Failure of ICI 182,780 treatment to exert an anti-oestrogen effect was excluded since uterine atrophy, loss of cancellous bone volume and the increase in osteoclast parameters were induced by administration of this compound. The absence of an increase in body weight in response to ICI $182,780 \mathrm{can}$ be explained on the basis that the compound does not exert an effect centrally (Wakeling 1993), but this fails to explain the absence of an effect on the other parameters. It is unlikely that the cells involved in bone formation and those responsible for regulating osteoclast formation/bone resorption express a different oestrogen receptor subtype, because Gallagher et al. (1993) have shown that ICI 182,780 inhibits the increase in bone formation induced by oestrogen administered to ovariectomised rats. Therefore, further study is required to resolve this apparent discrepancy.

The finding that animals treated with ICI $178,820 \mathrm{had}$ greater cancellous bone volume and reduced osteoclast numbers compared with the ovariectomised animals could not be attributed to conversion of endogenous androgens to oestrogens, because production of oestrogen in this way would have been ineffective, as its activity would have been antagonised by the anti-oestrogen. The failure to detect transcripts for P450 aromatase in bone and bonemarrow from any of the animals tested supports this view. We have, however, previously shown that mRNA for $\mathrm{P} 450$ aromatase is expressed in primary tissue from human fractures and in cultured human BM, which we have suggested is analogous to a wound (Lea et al. 1997). We 
were, therefore, able to exploit this information, and by showing that P450arom transcripts were detected in cultured rat BM, demonstrated that failure to detect mRNA in normal rat bone and BM could not be attributed to the probes being specific for the brain. It is unlikely that the failure to detect mRNA for P450arom was the result of technical failure, as RT-PCR is currently the most sensitive technique for detecting specific mRNA in low copy number. It is unusual to get false negative results, and we have excluded this possibility by using appropriate controls. Our results also show that adipose tissue is not a site for aromatisation in rats, whereas it is in humans, and this is consistent with previous reports (Simpson et al. 1994).

This study shows for the first time that ovarian androgens exert a minor but significant role in maintaining the female rat skeleton in the absence of oestrogen. The ovariectomised rat model is considered a suitable model for studying post-menopausal bone loss in the human (Kalu et al. 1989, Kalu 1991) because, just as in the rat (Wronski et al. 1988, Turner et al. 1994), low levels of oestrogen have been implicated as a major factor involved in low bone mass in the human (Christiansen et al. 1982, Richelson et al. 1984, Conte et al. 1994, Smith et al. 1994). Since it is well established that ovarian androgens are reduced as a result of ovariectomy and aging in humans (Judd et al. 1974) and rats (Lea \& Flanagan 1998), it is surprising that so little attention has been given previously to the role of these gender hormones in maintaining the female skeleton. However, if ovarian androgens were also found to protect against bone loss in oestrogen-deficient women, our findings may have important therapeutic implications.

\section{Acknowledgement}

This work was supported by The Arthritis and Rheumatism Council, UK.

\section{References}

Bruch H-R, Wolf L, Budde R, Romalo G \& Schweikert H-U 1992 Androstenedione metabolism in cultured human osteoblast-like cells. Journal of Clinical Endocrinology and Metabolism 75 101-105.

Bulun SE \& Simpson ER 1994 Competitive reverse transcriptionpolymerase chain reaction analysis indicates that levels of aromatase cytochrome $\mathrm{P} 450$ transcripts in adipose tissue of buttocks, thighs and abdomen of women increase with advancing age. Journal of Clinical Endocrinology and Metabolism 78 428-432.

Christiansen C, Christiansen MS, Larsen N-E \& Transbol I 1982 Pathophysiological mechanism of estrogen effect on bone metabolism: dose-response relationship in early postmenopausal women. Journal of Clinical Endocrinology and Metabolism $\mathbf{5 5}$ 1124-1130.

Conte FA, Grumbach MM, Ito Y, Fisher CR \& Simpson ER 1994 A syndrome of female pseudohermaphroditism, hypergonadotropic hypogonadism, and multicystic ovaries associated with missense mutations in the gene encoding aromatase (P450arom). Journal of Clinical Endocrinology and Metabolism 78 1287-1292.

Frisch RE, Canick JA \& Tulchinsky D 1980 Human fatty marrow aromatises androgens to estrogen. Journal of Clinical Endocrinology and Metabolism 51 394-396.

Furr BJA 1988 Pharmacological properties and potential clinical utility of ICI 176,334: a novel, non-steroidal, peripherally-selective antiandrogen. Amsterdam: Medicom Europe.

Furr BJA 1989 Casodex (ICI 176,334) - a new, pure, peripherallyselective antiandrogen: preclinical studies. Hormone Research 32 (Suppl 1) 69-76.

Furr BJA, Valcaccia B, Curry B, Woodburn JR, Chesterson G \& Tucker H 1987 ICI 176,334: a novel non-steroidal, peripherally selective antiandrogen. Journal of Endocrinology 113 R7-R9.

Gallagher A, Chambers TJ \& Tobias JH 1993 The estrogen antagonist ICI 182,780 reduces cancellous bone volume in female rats. Endocrinology 133 2787-2791.

Gallagher AC, Chambers TJ \& Tobias JH 1996 Androgens contribute to the stimulation of cancellous bone formation by ovarian hormones in female rats. American Journal of Physiology $\mathbf{2 7 0}$ E407-E412.

Goulding A \& Gold E 1993 Flutamide-mediated androgen blockade evokes osteopenia in the female rat. Journal of Bone and Mineral Research 8 763-769.

Judd GE, Lucas WE \& Yen SSC 1974 Endocrine function of the postmenopausal ovary: concentration of androgens and estrogens in ovarian and peripheral vein blood. Journal of Clinical Endocrinology and Metabolism 39 1020-1024.

Kalu DN 1991 The ovariectomized rat model of postmenopausal bone loss. Bone and Mineral 15 175-192.

Kalu DN, Liu C-C, Hardin RR \& Hollis BW 1989 The aged rat model of ovarian hormone deficiency bone loss. Endocrinology 124 $7-16$.

Lea CK \& Flanagan AM 1998 Physiological plasma levels of androgens reduce bone loss in the ovariectomized rat. American Journal of Physiology 274 E328-E335.

Lea C, Kendall N \& Flanagan AM 1996 Casodex (a non-steroidal antiandrogen) reduces cancellous, endosteal and periosteal bone formation in estrogen-replete female rats. Calcified Tissue International $\mathbf{5 8} 268-272$.

Lea CK, Ebrahim H, Tennent S \& Flanagan AM 1997 Aromatase cytochrome transcripts are detected in fractured human bone but not in normal skeletal tissue. Bone 21 433-440.

Lea CK, Moxham V, Reed MJ \& Flanagan AM 1998 Androstenedione treatment reduces loss of cancellous bone volume in ovariectomised rats in a dose-responsive manner and the effect is not mediated by oestrogens. Journal of Endocrinology 156 331-339.

Nawata H, Tanaka S, Tanaka S, Takayanagi R, Sakai Y, Yanase T, Ikuyama S \& Haji M 1995 Aromatase in bone cell: association with osteoporosis in postmenopausal women. Journal of Steroid Biochemistry and Molecular Biology 53 165-174.

Paech K, Webb P, Kuiper GJM, Nilsson S, Gustafsson JA, Kushner PJ \& Scanlan TS 1997 Differential ligand activation of estrogen receptors ER $\alpha$ and ER $\beta$ at AP1 sites. Science 277 1508-1510.

Plourde PV, Dyroff M \& Dukes M 1994 Arimidex: a potent and selective fourth-generation aromatase inhibitor. Breast Cancer Research and Treatment 30 103-111.

Plourde PV, Dyroff M, Dowsett M, Demers L, Yates R \& Webster A 1995 Arimidex: a new oral, once-a-day aromatase inhibitor. Journal of Steroid Biochemistry and Molecular Biology 53 175-179.

Purohit A, Flanagan AM \& Reed MJ 1992 Estrogen synthesis by osteoblast cell lines. Endocrinology 131 2027-2029.

Raisz LG, Wiita B, Artis A, Bowen A, Schwartz S, Trahiotis M, Shoukri K \& Smith J 1996 Comparison of the effects of estrogen alone and estrogen plus androgen on biochemical markers of bone formation and resorption in postmenopausal women. Journal of Clinical Endocrinology and Metabolism 81 37-43. 
Richelson LS, Heinze HW, Melton III LJ \& Riggs BL 1984 Relative contributions of ageing and estrogen deficiency to postmenopausal bone loss. New England Journal of Medicine 311 1273-1275.

Sarma U, Kendall A \& Flanagan AM 1995 Estrogen inhibits osteoclast formation in human bone marrow cultures. Bone $\mathbf{1 7}$ Abstract 83.

Sasano H, Uzuki M, Sawai T, Nagura H, Matsunaga G, Kashimoto O \& Harada N 1997 Aromatase in human bone tissue. Journal of Bone and Mineral Research 12 1416-1423.

Simpson ER, Mahendroo MS, Means GD, Kilgore MW, Hinshelwood MM, Graham-Lorence S, Amarneh B, Ito Y, Fisher CR, Micheal MD, Mendelson CR \& Bulun SE 1994 Aromtase cytochrome P450 enzyme responsible for estrogen biosynthesis. Endocrine Reviews 15 342-355.

Smith EP, Boyd J, Graeme RF, Takahashi H, Cohen RM, Specker B, Williams TC, Lubahn DB \& Korach KS 1994 Estrogen resistance caused by a mutation in the estrogen-receptor gene in man. New England Journal of Medicine 331 1056-1060.

Tobias JH, Gallagher A \& Chambers TJ 1994 5a-Dihydrotestosterone partially restores cancellous bone volume in osteopenic ovariectomized rats. American Journal of Physiology 267 E853-E859.

Tonetti DA, O'Regan R, Tanjore S, England G \& Jordan VC 1998 Antiestrogen stimulated human endometrial cancer growth: laboratory and clinical consideration. Journal of Steroid Biochemistry and Molecular Biology 65 181-189.

Turner RT, Riggs BL \& Spelsberg TC 1994 Skeletal effects of estrogen. Endocrine Reviews 15 275-300.

Vittek J, Altman K, Gordon GG \& Southren AL 1974 The metabolism of 17alpha-3-H-testosterone by rat mandibular bone. Endocrinology 94 325-329.

Wakeling AE 1993. The future of new pure antioestrogens in clinical breast cancer. Cancer Research Treatment 25 1-9.

Wakeling AE, Dukes M \& Bowler J 1991 A potent specific pure antiestrogen with clinical potential. Cancer Research 51 3867-3873.

Wronski TJ, Cintron M \& Dann LM 1988 Temporal relationship between bone loss and increased bone turnover in ovariectomized rats. Calcified Tissue International 43 179-183.

Yang NN, Bryant HU, Hardikar S, Sato M, Rachelle JS, Glasebrook AL \& Termine JD 1996 Estrogen and raloxifene stimulate transforming growth factor- $\beta 3$ gene expression: a potential mechanism for estrogen- or raloxifene-mediated bone maintenance. Endocrinology 137 2075-2084.

Received 28 May 1998

Accepted 7 September 1998 